\title{
USING INQUIRY-BASED LEARNING TO EXPLORE RESPECT OF CULTURAL BASE DESIGN: A CASE STUDY IN AMPHAWA TOURISM COMMUNITY, THAILAND
}

\author{
Natapon ANUSORNTHARANGKUL ${ }^{*}$ \\ King Mongkut's Institute of Technology Ladkrabang, Faculty of Architecture, Lat Krabang District, Bangkok, Thailand, email: natapon15@ hotmail.com \\ Yanin RUGWONGWAN \\ King Mongkut's Institute of Technology Ladkrabang, Faculty of Architecture, Lat Krabang District, Bangkok, Thailand, email: yaninrug@ yahoo.com
}

Citation: Anusorntharangkul, N., \& Rugwongwan, Y. (2021). USING INQUIRY-BASED LEARNING TO EXPLORE RESPECT OF CULTURAL BASE DESIGN: A CASE STUDY IN AMPHAWA TOURISM COMMUNITY, THAILAND. GeoJournal of Tourism and Geosites, 34(1), 164-169. https://doi.org/10.30892/gtg.34121-632

\begin{abstract}
Amphawa is a Thai valuable cultural heritage. This cultural tourism has been amplified thanks to the UNESCO award. Despite the recognition, there exists a conflict as seen obviously in the town development by cross-cultural designers. This research focuses on establishment of a proper learning model. Qualitative research was undertaken using a tool namely Ethnographic Delphi Futures Research. The results found that the method of Inquiry-Based Learning significantly made learners gain insights because of the direct interactions with the community stakeholders who truly take part in reaching the consensus which improved consistency of the design works to preserve the cul tural identity.
\end{abstract}

Key words: Culture-Based Design, Cross-Cultural Designers, Culture Lag, Ethnographic Delphi Futures Research, Inquiry-Based Learning

\section{INTRODUCTION}

Amphawa tourism community in Thailand is a community enriched with cultural heritage. Amphawa received international awards and grants to support its conservation of the cultural heritage (Peerapan et al., 2005). Amphawa is perceived as the top-rated tourist destination during weekends because of convenience of traveling (Peerapan, 2009) (not far from Bangkok). As a result, this community has created projects in developments of its physical environments and various service models to accommodate the increasing number of tourists (Seyanon, 2009). The positive impact is job creation and increased income of the community (Joseph et al., 2020). But in the attempt of tourism promotions, ways of thoughts and lifestyles of the local have changed rapidly causing cultural lag during such rapid developments (Tuntipornwanichkul et al., 2011). This is an adverse impact on the community. This research is motivated by a piece of news regarding the new establishment of the European-style-4-star hotel namely ChuchaiBuri Sri Amphawa Project. The hotel has been planned to locate in the middle of the Amphawa community. The architectural style of this project is in a complete contrast to the context of the Amphawa community. Consequently, it has been a debate that gained more attention from people in the community.

The Culture Lag (CL) is caused by an off-balance between prosperity of material culture and nonmaterial culture. There are several reasons leading to the occurrence of culture lag in cultural-tourism sites. One of the main reasons is the lack of stakeholders' engagement in reaching a consensus during the community development (Xavier, 2016). According to the paradoxical effect of visual perception theory (Zharikova et al., 2017) that describes a relation between human perception and the physical environment context (Gibson, 1979), the lack of engagement of stakeholders can cause misperception to tourists as a result of the undesirable changes in visual environments during the community development (Zarewa, 2019). Therefore, the consensus originated from the crucial information obtained from the community stakeholders is significant to designers allowing an appropriate design that harmoniously improve the physical environment with the way of life of the villagers in the community. Moreover, the design must meet the requirements of tourists. Since the development is engaged by people from different aspects, the problem of culture lag can be minimized. In design courses, fundamental subjects provide design knowledge, design technology, artistry, and design problems to guide and develop learners to become professional designers (Demirbaş and Demirkan, 2003). Based on the Active Learning (AL) approach, it can be practiced in two learning styles: Project-Based Learning (PjBL) and Problem-Based Learning (PBL). Both methods are considered as a Traditional Learning Approach (TLA). In this traditional approach, learners are supposed to follow a process after obtaining a design topic or a design problem. Necessary information is retrieved to analyze, summarize, synthesize, and create design works. Instructors themselves design both pedagogy styles. The instructors are likely to throw ideas or their preference styles into learners' design works. That is similar to a reflection or a transfer of their design preferences into learners (Zande et al., 2014). As a result, the learners' design works become inconsistent with the design context in terms of timing and spatial especially in the Culture-Based Design (CBD).

From the literature review, the Inquiry-Based Learning (IBL) is a participatory approach that allows learners to create their inquiries in the purpose of gaining insights of the subject content (Voet and De Wever, 2019). The objective of the Inquiry-Based Learning is, in fact, not to find an answer but to find a proper solution in each story content. It also changes an attitude from "what we know" to "how we come to know" (Salama, 2010). In this learning style, instructors perform as a facilitator (Bonwell, 1996). Learners can attain knowledge by making inquiries, investigating, and finding various methods until they reach meaningful comprehension (Keeton and Tate, 1978). As seen from these, it is a long-term knowledge gain method that can be utilized to solve problems effectively.

This research paper focuses on implementation of the Inquiry-Based Learning method into the teaching and learning in the CultureBased Design course. This learning method aims to provide learners with depth insight that cannot be obtained via the Traditional Learning Approach method. Learners receive authentic information from the cultural community via the inquiries. This can eliminate the problem of forcing the instructor's thoughts into the learner's work as the learners can always double check with the villagers from whom they received the information. Therefore, the information is a consensus of stakeholders' engagement prior to the next step of design. This process also reduces the problem of the visually ugly design and the conflicts with Culture-Based Design works. 
Aim of the research. This research aims to compare the Inquiry-Based Learning and the Traditional Learning Approach in solving problems emerging from the research process and data collection of Cross-Cultural designers. Designers who have working experience typically will accumulate knowledge until they have their unique approach or form (Alaswad, 2019). They frequently use their uniqueness into the Culture-Based Design work which undermines the cultural identity that is supposed to be conveyed. For this reason, stakeholders have denied a consensus of the Culture-Based Design works. The research question was, "Can the Inquiry-Based Learning approach be applied to the teaching and learning in the Culture-Based Design course which focuses on the research process and data collection of cultural identity for achieving mutual acceptance among stakeholders of the cultural tourism community?"

\section{METHODOLOGY}

The research method was a qualitative research, which was the grounded theory. The research tool was the data collection and interview of the Amphawa community stakeholders. These reduce the chance of conflict between the community villagers and the community outsiders (as seen in the hotel design that does not blend in with the community environment). The researcher chose to use the Inquiry-Based Learning in conjunction with the design process focusing research process and data collection of learners (Duran and Dökme, 2016). In this situation, the learners interacted between the informant and the environment during the collection of information. They had been able to extract and show the essential and accurate information of the cultural identity. This method will have followed the participatory design paradigm.

\section{Research Design}

The instructor suggested additional methods for collecting data beyond the past processes when learners made questions and jointly defined the studied subject's scope and details. Questions were issues and problems arising in the Amphawa community, which the instructor had stimulated learners. The instructor recommended using the Ethnographic Delphi Futures Research (EDFR) with three informants to encourage greater interaction between learners, the community people and environment than regular data collection.

The Ethnographic Delphi Futures Research is a research technique that combines the Ethnographic Futures Research (EFR) and the Delphi Technique (Charoenphut and Chirinang, 2015). It has strengths and advantages. The Ethnographic Delphi Futures Research processes are similar to the Ethnographic Futures Research, but the Ethnographic Delphi Futures Research interviews are more flexible. Open-ended questions are prepared in advance in order to get the appropriate answers matching the research goals.

In the first interview, the Ethnographic Delphi Futures Research interview method was the instructor-recommended method for researching and collecting data. The learners used in-depth interviews with informants are experts who are involved in the Amphawa community in three groups. Three members were from each group - the instructor recommended the qualified professionals to learners. In this step, learners prepared the topic of open-ended questions in advance. During the interview, learners noted and recorded the audio by notified experts in advance. The first interview time was 90 minutes per person. Those topics divided into two issues, viz. the way of Amphawa people's life from the past until the present and the physical environment identity of a row of traditional wooden Amphawa houses lining a canal (RTW-AH). Color, material and surfaces, lighting, decorative items, decoration, and void were key points of the physical environment identity of a row of traditional wooden Amphawa houses lining a canal.

They would have analyzed content and transcript from the recorded audio files when they finished all interviews. They checked duplicate words of the two significant issues from all informants - those duplicates were used as a factor to create a query in the next interview.

In the second interview, learners went back and asked the nine informants to find each issue's duplicate words' rating scale. In this step, they used questionnaires. In its questionnaire form, the Likert scale is a 5-point scale used to allow the individual to express the extent they agree or disagree with a duplicate word. Learners also interviewed the reasons for their rating scale of informants. This step's finalized results were representative of the community's cultural identity, which used the results of the interviews explained. When the duplicate words' analysis results were consistent, they used it to create a query in the third interview. In the third interview, the famous duplicate words were in the questionnaires with the 5-point Likert scale. The results of this step were the ranking of each issue. Experts chose one duplicate word that they think was the ultimate uniqueness representation and confirmed the answer by explaining the reasons.

Consensus checking of the Amphawa cultural identity representative was keywords from 7 factors. These reviews again find a consensus on the representation with 2 groups: 10 villagers who have lived in the Amphawa community for more than 10 years and thirty tourists who have experienced traveling and stayed in the Amphawa community. The research tool was the questionnaires with the 5points Likert scale. Informants also had to explain the reasons for their answers. The results were analyzed using descriptive statistics by finding the Mean and Standard Deviation (S.D.). These results described the accepted level to the collective cultural identity information and used the respondents' explaining results to describe the phenomenon that occurred.

\section{Participants}

1. Twelve participants of the third-year undergraduate learners in the interior and exhibition design department, Suan Sunandha Rajabhat University, as representatives of a Cross-Cultural designer, who volunteer or are interested in participating in this research. These participants had the design knowledge but no experience in the Culture-Based Design and never lived in the Amphawa community. Their age was between 19-22 years old; 6 women and 6 men. They had to collect information for using in their design, which are the terms and conditions for this group. Learners in this group have passed an introductory design course. They have also passed the design process by lectures from instructors and have already designed small projects. They had the skills to conduct research and collect data for their design process in the next step.

2. Informants involved in the Amphawa community are experts, divided into 3 groups: 1) the community villagers who were born and live there and have owned a row of traditional wooden Amphawa houses lining a canal, 2) instructors in the field of the CultureBased Design, and 3) interior environment designers who have experienced in design related to the Culture-Based Design. Three members are chosen from each group. The sampling was purposive that the instructor recommends the qualifications of informants. After that, the learners contacted and met with the experts.

3. Respondents, a stakeholder providing consensus data concerning Amphawa identity, were divided into 2 groups: 1 ) the community villagers who have lived in the Amphawa community for more than 10 years (10 participants) and 2) tourists who have experienced traveling and stayed in the Amphawa community (thirty participants). In this research, the researcher's role was the creator of attention and the mentor to learners. The researcher facilitated the research and collection of information in the area for the learners.

\section{Research Area}

This research has divided into 2 parts according to the research process. The first research area was the classroom activity area where teaching activities by the Inquiry-Based Learning took place. The first step was to generate the engagement using focused group discussions concerning problems of the Culture-Based Design. As the motivator, the instructor encouraged learners to create questions about the 
Amphawa community issues and problems as appeared in the newspaper. When learners asked the interesting questions, they defined the scope and enumerated details of the studied subject. In this case, they researched and gathered the outstanding cultural identity knowledge of the Amphawa community. The scope was the villagers' life of the community and the physical identity of a row of traditional wooden Amphawa houses lining a canal for using in the design process in the next step. Learners explored and searched the data that is the second step of the Inquiry-Based Learning when they already defined the collecting data area. Therefore, the second research area was the Amphawa community. Learners interviewed and recorded data with three groups of experts and asked for villagers' and tourists' opinions. All data collection steps were within the Amphawa community for encouraging the interaction between people and their environment within the community.

\section{PROCESS}

This section presents the teaching steps to compare the Inquiry-Based Learning and Traditional Learning Approach methods which were used and divided according to key points of learning management.

\section{Assignment}

In the Inquiry-Based Learning method, the instructor opened issues to motivate learners using events related to the course content. This process caused learners to ask questions that led to research for answers. In this research, the instructor cited the conflicting news between villagers and stakeholders in Amphawa cultural tourism community and outside capitalists. Outside capitalists were those who built hotels using the contradicted design guidelines to the community context. This situation has resulted in the Culture Lag due to the destruction of buildings that represented the community identity. Furthermore, villagers were evacuated from their communities.

The learners shared various opinions and exchanged details about the causes of the conflict and the arising problems.

"Amphawa already has a pretty clear identity. Why was it not used in the design that can confirm the evidential of Amphawa identity?"

"The travelers visited Amphawa because they wanted to experience the atmosphere of past Amphawa, weren't they? If they were to experience another different atmosphere, why would they need to go to Amphawa?"

These are examples of what the students debated. The instructor continued asking questions so that the students could give their frame of ideas and clarified questions. That led to the formulation of an appropriate assignment of the work topic to the course content and time.

"What is the Amphawa atmosphere?"

"What is the evidential identity of Amphawa that the villagers and stakeholders mutually accept?"

The instructors' questions had influence in motivating learners to actively find a representation of the Amphawa community identity that the villagers and stakeholders mutually accepted which was used as important information for design work. However, there still was a problem because the socio-cultural identity had a vast meaning. The instructor then added questions to formulate an appropriate scope to the time of the learning period making learning boundaries more concise and clearer.

"What aspects of identity should be searched for using in the most suitable interior design work?"

The learners had researched the information and debated to find the answers again until they reach conclusion. As follows:

"A row of traditional wooden Amphawa houses lining a canal is the Amphawa community's distinctive architectural identity since Amphawa was the floating market in the past.It received the UNESCO Asia-Pacific Awards for Cultural Heritage Conservation .Moreover, the villagers' lifestyle is also impressive for tourists."

Those were the two main areas that learners set and were eager to search for learning. In the Traditional Learning Approach method, the instructor determined the design topic for the learners.

"Learners work on the interior design of a local restaurant by using the concept from a row of traditional wooden Amphawa houses lining a canal."

The learners performed the work according to the design process that they had previously learned when they received the topic and all requisitions from the instructor. These include 1) the problem determination, 2) the research and collection of information, 3) the conceptual development, 4) task creation and 5) the work presentation. All these are a design process that all learners have be en familiar with. Moreover, the instructor recommended researching and collecting a row of traditional wooden Amphawa houses lining a canal information for the definiteness of both learning groups' research processes and data. That is based on six key points, e.g. color, material and surfaces, lighting, decorative items, decoration, and void.

\section{Data Collection}

In survey and search process of the Inquiry-Based Learning method, the instructor recommended the learners to stay in the row of traditional wooden Amphawa houses lining a canal where has been converted to a homestay. Learners collected data by the Ethnographic Delphi Futures Research method with three groups of experts. All interviews conducted in the Amphawa community for emphasizing the interaction between learners and community stakeholders. They combined them with researching information from documents, textbooks, and internet contents. After that, learners made a plan to determine the guidelines and duration of the process themselves. In Traditional Learning Approach method, the instructor guided the information sources to learners. The learners mainly search for information from documents, textbooks, and internet content. They went to the Amphawa community area that they only photographed, measured, and collected the row of traditional wooden Amphawa houses lining a canal building sizes. In this method, learners and community stakeholders had little interaction. In both methods of teaching and learning, the instructor was only responsible for observing. The instructor was not participating in the interview process and data collection. The instructor gave advice only when learners had problems.

\section{Explanation}

The information obtained from the Inquiry-Based Learning method was important information that were received directly from villagers and stakeholders in the Amphawa community. That information was profundity, evident, and specific. It was reexamined three ti mes by the Ethnographic Delphi Futures Research procedure with experts and repeatedly inquired with villagers and tourists. All these processes; thus, got a consistent consensus (Alalou et al., 2016). Therefore, the obtained information was credible. Learners' information con tents that they concluded and presented to the instructor were profundity. The data of each factor explained all the referable reasons. The instructor was served only to inquire about the issues that needed more details. The instructor did not suggest or show any comments about the learners' 
information. In Traditional Learning Approach method, the primary source of the obtained information was from the Internet. Learners researched and used the obtained information to brainstorm, analyze, debate for summarizing data. The instructor explained with examples from his/her own experience when learners presented information. However, the content lacked profundity, apparent content, and had the unclear reasons. The instructor may have intervened with ideas or preference style into learners' design work. As a result, learners were familiar with cursory researching and receiving information, which would affect their future works.

\section{RESULTS}

This part presents the researcher's findings and learners' collection of information, including the analysis and presentation to compare the profundity of information between using the Inquiry-Based Learning and Traditional Learning Approach method and dividing the findings according to learners' searching factors.

\section{Lifestyle Factor}

The Inquiry-Based Learning group described the villagers' lifestyles up to 3 generations. Because of the opportunity to talk with the villagers who were born and have lived in the community.

"Amphawa was a large trading community 70 years ago.There was the main water transportation.There were many boats for trading and exchanging goods in the canal.People can walk across the canal by walking on a hull floating on the water.Many RTW-AH were along the two sides of the canal.Villagers started trading in the early morning and dwindled in the late morning. "Anong Krit-Nan said, is 79 years old, is her tiny interview part.

"Around 1977, a row of traditional wooden Amphawa houses lining a canal became a cheap rental room . When I was young, I ran around here. There were very few boats because more widespread freight cars were used.The market moved up to the ground .The villagers infrequently paddled a boat carrying goods for sale in the past. Some row of traditional wooden Amphawa houses lining a canal has been demolished to create modern buildings .The floating market was just restored in 2004." Some interview part of Parinya Phruek-HatthaPhong, who is 45 years old.

"I was born and saw already this jolly market condition. There were many tourists here. The villagers traded enjoyably, but the number of villagers began to decline recently. There are outsiders, who are not Amphawa people, rented area for trading. Food products are expensive because of the high price of the rent." Sophon Si-Rat, who is 25 years old, said.

The Traditional Learning Approach learning group, the primary source of the obtained information, was from the document and the Internet. That information lacked profundity and could not provide the changes from the past to the present.

The Amphawa community has stagnated in the 21 st century as a result of changing the means of transportation.

On August 11, 2004, Amphawa Floating Market was restored by Amphawa Subdistrict Municipality, Samutsongkram, and the community.

Community and Amphawa Floating Market, Samutsongkram, is rural tourism/village tourism. It was highly popular in 2010, according to the ranking from Tourism Authority of Thailand (TAT) Booklet.

These data were obtained from The Conservation and Revitalization of Amphawa Community monograph, December 2008. The research results found that the information obtained from the Inquiry-Based Learning method connected directly with experiences of the local who truly witness evolution of Amphawa in each era. Some in-depth information can even explain the causes of the happened incidents. This information was not revealed in online documents which could be obtained merely from community villagers.

\section{Color, Material and Texture Factor}

Teak, Siamese Sal, and Ironwood were the specific color and materials that learners could identify. This was attributed to undertaking the Ethnographic Delphi Futures Research with villagers and stakeholders in the Inquiry-Based Learning method. Besides, learners could identify the color and the material and the locations where the materials were often used.

"The wooden folding doors of the front of a row of traditional wooden Amphawa houses lining a canal must use teak because it is gorgeous. It looks good and deluxe. The wood surface is only coated with the wood treatment oil, that is enough." Thonphat Bunsanan said.

For his interview part, Prasitthichai Kanokthianthana said, "For the walls and floors were mostly made from Redwood and Siamese Sal. Other types of wood have been seen, but rarely. The wood surface was glossy from rubbing and wiping for such a long time."

The color and the texture of wood used in a row of traditional wooden Amphawa houses lining a canal have been reconditioned often, concluding from the Traditional Learning Approach learning group learners. They concluded from what they saw. This conclusion was most likely caused by inadequate access to the data source leading to a lack or false of the obtained details.

\section{Lighting Factor}

Natural lighting shined in by opening the wooden folding doors installed at the front of a row of traditional wooden Amphawa houses lining a canal. During daytime, the inside environment received sufficient natural light. In the past, inhabitants generated warm light from kerosene pressure lanterns, kerosene lanterns, and antique oil lamps during nighttime. Nowadays, artificial light was u sed. Daylight was used in the work area whereas warm light was used for creating the atmosphere. This data above was found and presented by the Inquiry-Based Learning group. The Traditional Learning Approach learning group concluded that artificial lighting was not turned on in daytime. On the other hand, inhabitants used artificial lighting at nighttime. The main source of light used in daytime is natural light.

\section{Decoration and Decorative Items Factor}

The Inquiry-Based Learning group obtained information regarding this factor by data collection as follows:

"The main utility of a row of traditional wooden Amphawa houses lining a canal building was for commercial purposes. Decorations and decorative items were the simple styles of furniture, for instance, product showcase. Over time, those things and furniture have become valuable antique." Sarath Simsiri said.

For some interview part, Khwanrat Chinda said, "A kerosene pressure lantern, kerosene lantern, antique oil lamp, antique brassware, vintage gramophone, vintage sewing machine and traditional bamboo fish trap, which once used in daily life, have transformed into decorative items. That is a change of function and value when the time passed."

Tools and furniture in the past have been used in interior decoration today; this is the conclusion of the Traditional Learning Approach learning group. 


\section{Void Factor}

The Inquiry-Based Learning group presented that there was trading along the waterfront in the past. That void of the wooden folding doors was wide opened is an apparent identity of a row of traditional wooden Amphawa houses lining a canal. Therefore, it was necessary to be opened. The top of the wooden wall installed with a ventilator above the door also helped ventilate and removed moisture when the door was closed. Since the building is located along the canal, the atmosphere is humid. If the air could not circulate, people could feel uncomfortable due to a sticky-feel moisture. In the Traditional Learning Approach learning group, conclusion made for the wooden folding doors was that the wooden wall was installed with a ventilator above the door. However, they did not give the reason of the installation of the ventilator.

Table 1. The conclusion of results of the data collection and research: comparison of two learning groups (Inquiry-Based Learning VS Traditional Learning Approach)

\begin{tabular}{|c|c|c|c|}
\hline \multirow{8}{*}{ 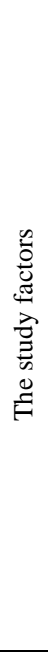 } & & Inquiry-Based Learning & Traditional Learning Approach \\
\hline & Lifestyle & $\begin{array}{l}\text { Explaining the community changes from the data collected from people with } 3 \\
\text { different ages who were born and have lived in the community. }\end{array}$ & $\begin{array}{l}\text { Summary of changes came from document and the } \\
\text { internet, but the connections between the changes } \\
\text { and what caused the changes were not mentioned. }\end{array}$ \\
\hline & Color & $\begin{array}{l}\text { The colors of real wood were specific with the types of wood e.g. Teak, Siamese Sal } \\
\text { and Ironwood }\end{array}$ & They only know the color of real wood. \\
\hline & $\begin{array}{l}\text { Material } \\
\text { and } \\
\text { Texture }\end{array}$ & $\begin{array}{l}\text { Wood e.g. Teak, Siamese Sal, and Ironwood have been identified as the material and } \\
\text { the used position was recorded. For example, the Teak wooden folding doors and } \\
\text { Redwood floor. The wood surface was glossy from rubbing and wiping for a long } \\
\text { time, or the wood surface coated with the wood treatment oil. }\end{array}$ & $\begin{array}{l}\text { Summary as Wood, Wood Surface and Color of } \\
\text { wood }\end{array}$ \\
\hline & Lighting & $\begin{array}{l}\text { During daytime, the inside environment received sufficient } \mathrm{n} \\
\text { source was a lantern during the nighttime. Now, artificial war }\end{array}$ & $\begin{array}{l}\text { Natural light was used in daytime whereas } \\
\text { artificial lighting was used at night. }\end{array}$ \\
\hline & $\begin{array}{l}\text { Decorative } \\
\text { items }\end{array}$ & $\begin{array}{l}\text { Functions of tools used in daily life and their values had been transformed when the } \\
\text { time passed. The tools were transformed into decorative items, such as a kerosene } \\
\text { pressure lantern, kerosene lantern, antique oil lamp, antique brassware, vintage } \\
\text { gramophone, and vintage sewing machine, and a traditional bamboo fish trap. }\end{array}$ & $\begin{array}{l}\text { Tools and furniture in the past were used as } \\
\text { interior decoration now. }\end{array}$ \\
\hline & Decoration & Everyday life furniture, Simple wooden furniture, Products showcase & Simple wooden furniture \\
\hline & Void & $\begin{array}{l}\text { The void of the wooden folding doors was wide opened because of trading along the } \\
\text { waterfront in the past. The top of the wooden wall vent installed with a ventilator } \\
\text { above the door helped ventilate and remove moisture. }\end{array}$ & $\begin{array}{l}\text { The void of the wooden folding doors was wide } \\
\text { opened and the top of the wooden wall was } \\
\text { installed with a ventilator. }\end{array}$ \\
\hline
\end{tabular}

From the Table 1, it was found that the Inquiry-Based Learning group presented obvious and profound information. In-depth explanations were observed compared to the superficial information obtained from the Traditional Learning Approach learning group. This resulted from the interaction of learners with villagers and stakeholders in the Amphawa community. During the collection of information, learners were in the community area - causing them to absorb the context of physical environment which allowed connections between their newly earned knowledge with clear insights of the community context.

\section{Consensus}

After concluding the data analysis of the Ethnographic Delphi Futures Research procedure, the Inquiry-Based Learning group also took keywords of the eight factors to search for a consensus with two groups of informants. There were forty informants. The research tool was the questionnaires with the 5-point Likert scale.

Table 2. The data analysis of the Ethnographic Delphi Futures Research procedure

\begin{tabular}{|c|c|c|c|c|c|c|}
\hline Factors & & Identity & Mode & $\square$ & $\mathrm{SD}$ & Prominent Level \\
\hline \multirow{2}{*}{ 1. Lifestyle } & 1.1 & An atmosphere of the evening floating market & 5 & 4.22 & 0.83 & Well \\
\hline & 1.2 & The activity; Boat trip, Watching Firefly and Giving alms to a Buddhist monk & 5 & 4.67 & 0.5 & Maximum \\
\hline \multirow{3}{*}{ 2. Color } & 2.1 & Brown color of real wood & 5 & 5.00 & 0.00 & Maximum \\
\hline & 2.2 & Color of wood; Teak, Siamese Sal and Ironwood & 5 & 4.78 & 0.44 & Maximum \\
\hline & 2.3 & Color of wood coat with the wood treatment oil & 4 & 4.11 & 0.60 & Well \\
\hline \multirow{3}{*}{$\begin{array}{l}\text { 3. Material } \\
\text { and Texture }\end{array}$} & 3.1 & Real wood surface & 5 & 4.67 & 0.50 & Maximum \\
\hline & 3.2 & Wood surface is glossy from rubbing and wiping & 5 & 5.00 & 0.00 & Maximum \\
\hline & 3.3 & Wood surface coat with the wood treatment oil & 5 & 4.56 & 0.53 & Maximum \\
\hline \multirow{3}{*}{ 4. Lightning } & 4.2 & Lighting from a kerosene pressure lantern and kerosene lantern & 5 & 4.89 & 0.33 & Maximum \\
\hline & 4.3 & An artificial light is warm lights & 5 & 4.44 & 0.73 & Well \\
\hline & 4.4 & Dim light & 4 & 4.00 & 0.71 & Well \\
\hline \multirow{3}{*}{$\begin{array}{l}\text { 5. Decorative } \\
\text { items }\end{array}$} & 5.1 & Old photos of Amphawa past & 5 & 4.67 & 0.71 & Maximum \\
\hline & 5.2 & Tools in the past; lantern, antique brassware, vintage gramophone and vintage sewing machine & 5 & 4.89 & 0.33 & Maximum \\
\hline & 5.3 & Tools and equipment used in the past; Wicker & 5 & 4.67 & 0.71 & Maximum \\
\hline \multirow[b]{2}{*}{ 6. Decoration } & 6.1 & Furniture for occupation & 5 & 4.33 & 0.71 & Well \\
\hline & 6.2 & Furniture for everyday life & 5 & 4.67 & 0.71 & Maximum \\
\hline \multirow{3}{*}{ 7. Void } & 7.1 & Wooden folding doors open and see a canal & 5 & 5 & 0 & Maximum \\
\hline & 7.2 & Ventilator above the door & 5 & 4.67 & 0.5 & Maximum \\
\hline & 7.3 & Ventilator vent on the top of wall & 4 & 4.22 & 0.67 & Well \\
\hline
\end{tabular}

Table 2 demonstrates concluding results of a consensus representing the Amphawa community cultural identity. The lifestyle and physical identity of a row of traditional wooden Amphawa houses lining a canal were a confirmation of accepting the information prior to the design in the next step which can be implied that this process reduced conflicts in the design process.

\section{CONCLUSION}

This research aimed to apply the Inquiry-Based Learning method to the teaching of the Culture-Based Design course, focusing on the research process and data collection of cultural identity for achieving mutual acceptance among stakeholders of the cultural tourism 
community. This research adopted the Inquiry-Based Learning method to develop teaching for the Culture-Based Design course. The results found that the Inquiry-Based Learning group presented the profound results of the data collection process when compared to the Traditional Learning Approach method. The instructor acted only as an instructor and facilitator. He/she had no opportunity of forcing the instructor's thoughts or ideas into the learners' discovery. The knowledge gained by learners was established based on their hands-on experience (Paul et al., 2006) which was accurate since the knowledge was originated from the true context of community.

Learners comprehended the real context in the community area where they surveyed and collected data. Learners had related the events with knowledge gained through searching, causing a good understanding of the meaning of what they were studied. These results were demonstrated by their explanations while presenting their works to their teacher.

The obtained information from the Ethnographic Delphi Futures Research which was designed to attain the most reliable consens us from experts was reinvestigated with the community stakeholders. The reinvestigation was to confirm the reliability of the consensus which eliminated conflicts of discovered information. Cross-Cultural designers should emphasize the process of researching and collecting information directly to reduce the conflicts of Culture-Based Design works (Buil et al., 2012). Obtaining information from documents, textbooks, or the internet may not be sufficient because of the designer's lack of interaction with the actual community context. Those designers, who have work experience, always forced their ideas or preference styles into their design works. This was a major cause of the wrong interpretation of Culture-Based Design work resulting in the observation of culture lag in the community of cultural tourism such as Amphawa.

\section{Acknowledgements}

The author's sincere thanks go to the advisor, Assistant Professor Dr. Yanin Rugwongwan for the support of study and related research. Their guidance helped during all the time of research. The author also wishes to thank the various students who volunteer or are interested in participating in this research, as agents of a Cross-Cultural designer.

\section{REFERENCES}

Alalou, W.S., Liew, M.S., \& Zawawi, N.A.W.A. (2016). Identification of coordination factors affecting building projects performance. Alexandria Engineering Journal, 55, 2689-2698. http://dx.doi.org/10.1016/j.aej.2016.06.010

Alaswad, Z. (2019). A case study of game-based learning in interior design studios. Design and Technology Education: An International Journal, 24(3), 3151. https://ojs.lboro.ac.uk/DATE/article/view/2562

Bonwell, C.C. (1996). Enhancing the lecture: revitalizing a traditional format. New Directions for Teaching and Learning, 67, 31-44. https://doi.org/10.1002/t1.37219966706

Buil, I., Chernatony, L.D. \& Martínez, E. (2012). Methodological issues in cross-cultural research: An overview and recommendations. Journal of Targeting, Measurement and Analysis for Marketing, 20, 223-234. https://doi.org/10.1057/jt.2012.18

Charoenphut, W., \& Chirinang, P. (2015). Kan wichai choeng anakhot duai theknik den fai [Future research techniques; delphi technique]. Western University Research Journal of Humanities and Social Science, 1(3), 26-40 (in Thai)

Demirbaş, Ö.O., \& Demirkan, H. (2003). Focus on architectural design process through learning styles. Design Studies, 24(5), 437-456. https://doi.org/10.1016/S0142-694X(03)00013-9

Duran, M., \& Dökme, İ. (2016). The effect of the inquiry-based learning approach on student's critical-thinking skills. Eurasia Journal of Mathematics, Science \& Technology Education, 2016, 12(12), 2887-2908. https://doi:10.12973/eurasia.2016.02311a

Gibson, J.J. (1979). The ecological approach to visual perception. Boston: Houghton Mifflin. https://doi.org/10.1002/bs.3830260313

Joseph, E.K., Kallarakal, T.K., Varghese, B., \& Antony J.K. (2020). Sustainable tourism development in the Backwaters of South Kerala, India: The Local Government Perspective. GeoJournal of Tourism and Geosites, 33(4spl), 1532-1537. https://doi.org/10.30892/gtg.334spl13-604

Keeton, M.T., \& Tate, P.J. (1978). Learning by Experience-What, Why, How. San Francisco: Jossey-Bass.

Paul A. K., Sweller, J. \& Clark, R. E. (2006). Why Minimal Guidance During Instruction Does Not Work: An Analysis of the Failure of Constructivist, Discovery, Problem-Based, Experiential, and Inquiry-Based Teaching Educational Psychologist, 41(2), 75-86. https://doi.org/10.1207/s15326985ep4102_1

Peerapan, W. (2009). Changes in the use of canalside buildings on Amphawa Canal, Samut Songkhram Province: The consequences of conservation and development project from 2001 to 2009. Nakhara: Journal of Environmental Design and Planning, 5, 23-38. https://ph01.tci-thaijo.org/index.php/nakhara/article/view/104995

Peerapan, W., Lao Kaeo Nu, T. \& Sisarakham, S. (2005). Amphawa Samut Songkhram Khwam Pen Yu Lae Prapheni [Amphawa (Samut Songkhram) - life

and tradition]. Bangkok: Faculty of Architecture, Chulalongkorn University, 59 (in Thai).

Salama, A.M. (2010). Delivering theory courses in architecture: Inquiry-based, active, and experiential learning integrated. ArchNet-IJAR, International Journal of Architectural Research, 4(2/3), 278-295. https://doi:10.26687/archnet-ijar.v4i2/3.111

Seyanon, A. (2009). Kan pongkan kan sueamsom lae kan anurak sapphayakonthammachat lae singwaetlom khong talatnam Amphawa [The Prevention of Deterioration and Natural Resources and Environmental Conservation of Amphawa Floating Market]. University of the Thai Chamber of Commerce Journal, 29(4), 163-172 (in Thai).

Tuntipornwanichkul, S., Jongkroy, P., \& Kaveeta, L. (2011). Kan plianplaeng withichiwit chak kan phatthana kan thongthiao tambon Amphawa, Samut Songkhram [Livelihood Changes by Tourism Development in Tambon Amphawa, Changwat Samut Songkhram]. The proceeding of $49^{\text {th }}$ Kasetsart University Annual Conference: Humanities and Social Sciences, 49, 215-222 (in Thai).

Voet, M. \& De Wever, B. (2019). Teachers' adoption of inquiry-based learning activities: The importance of beliefs about education, the self, and the context. Journal of Teacher Education, 70(5), 423-440. https://doi.org/10.1177/0022487117751399

Xavier, M.S. (2016). A Kalieodoscopic view of cultural lag and society. Paripex-Indian Journal of Research, 5(3), 371-372. https://doi.org/10.36106/paripex

Zande, R.V., Lauren W., Nikoomanesh, B., \& Dexter, K.V. (2014). The design process in the art classroom: Problem-solving skills for life and careers. Art Education. 2014, 67(6), 20-27. https://doi.org/10.1080/00043125.2014.11519294

Zarewa, G. A. (2019). Barriers to Effective Stakeholder Management in the Delivery of Multifarious Infrastructure Projects (MIPs). Journal of Engineering, Project, and Production Management 2019, 9(2), 85-96. https://doi.org/10.2478/jeppm-2019-0010

Zharikovaa, A., Gepshteinb, S. \& Leeuwen, C. V. (2017). Paradoxical perception of object identity in visual motion. Vision Research, 136(2017), 1-14. https://doi.org/10.1016/j.visres.2017.04.008 